\title{
Design Optimization of a Variable-Speed Power-Turbine
}

\author{
Eric S. Hendricks, ${ }^{*}$ Scott M. Jones ${ }^{\dagger}$ and Justin S. Gray ${ }^{\ddagger}$ \\ NASA Glenn Research Center, Cleveland, Ohio, 44135
}

\begin{abstract}
NASA's Rotary Wing Project is investigating technologies that will enable the development of revolutionary civil tiltrotor aircraft. Previous studies have shown that for large tiltrotor aircraft to be viable, the rotor speeds need to be slowed significantly during the cruise portion of the flight. This requirement to slow the rotors during cruise presents an interesting challenge to the propulsion system designer as efficient engine performance must be achieved at two drastically different operating conditions: takeoff and cruise. One potential solution to this challenge is to use a transmission with multiple gear ratios and shift to the appropriate ratio during flight. This solution will require a large transmission that is likely to be maintenance intensive and will require a complex shifting procedure to maintain power to the rotors at all times. An alternative solution is to use a fixed gear ratio transmission and require the power turbine to be designed to operate efficiently over the entire speed range. This concept is referred to as a variable-speed power-turbine (VSPT) and is the focus of the current study. This paper explores the design of a variable-speed power-turbine for civil tiltrotor applications using design optimization techniques applied to NASA's new meanline tool, the Object-Oriented Turbomachinery Analysis Code (OTAC).
\end{abstract}

\section{Nomenclature}

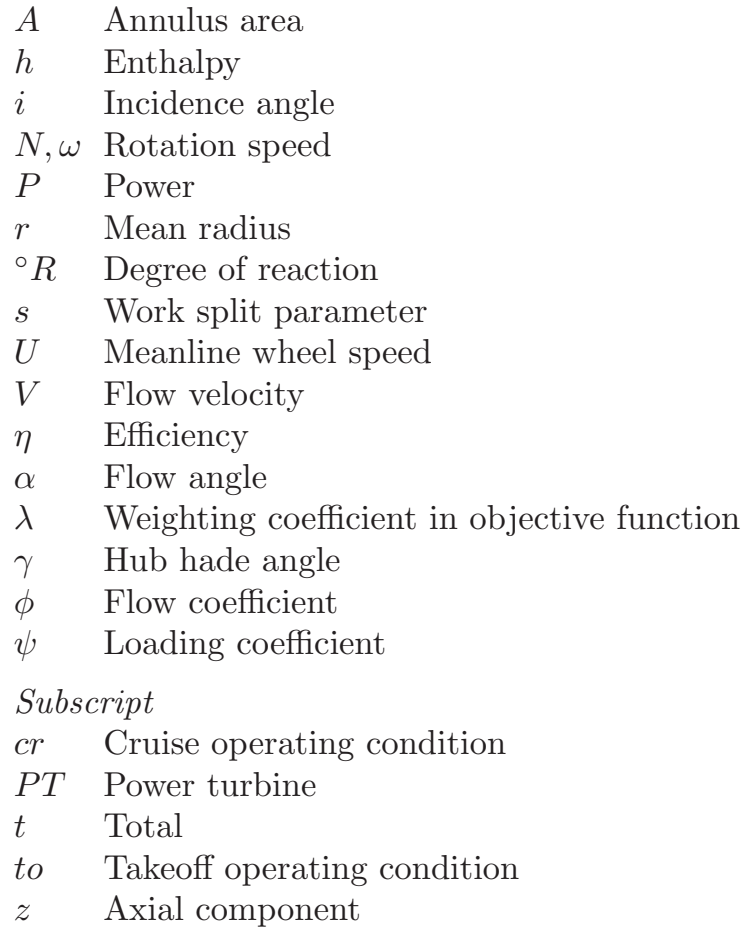

*Aerospace Engineer, Propulsion Systems Analysis Branch, MS 5-11.

$\dagger$ Aerospace Engineer, Propulsion Systems Analysis Branch, MS 5-11, AIAA Member.

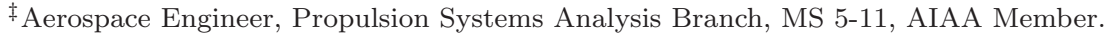




\section{Introduction}

TASA's Rotary Wing Project is focused on researching and developing technologies which will enable 1 future revolutionary vertical lift commercial aircraft with the broader goal of enhancing the air transportation system. ${ }^{1}$ One of the vehicle concepts being explored by the project to address this objective is the tiltrotor. The tiltrotor vehicle has been studied extensively by the Rotary Wing Project with initial sizing and critical technology development areas being identified. ${ }^{2,3}$

One of the primary technical challenges identified by these previous studies that requires further investigation relates to the propulsion system. The propulsion system on tiltrotor aircraft is made up of a large rotor/propeller, gearbox and turboshaft gas turbine engine. Studies on the rotor/propeller have shown that the best performance is achieved by operating the rotor at high speeds during takeoff to produce vertical lift. ${ }^{2}$ However, during forward flight when the rotor is operating as a large propeller, the best performance is achieved by significantly slowing the rotation speed of the the propeller. This characteristic of improved rotor/propeller performance can be seen in Figure 1. The challenge comes in how to provide power from the turboshaft engine via the gearbox across this potentially large range of rotor speeds. As Figure 1 also shows the power turbine becomes less efficient at lower rotation speeds. As a result, the propulsion system may need to be operated at a higher rotation speed to achieve the best overall performance.

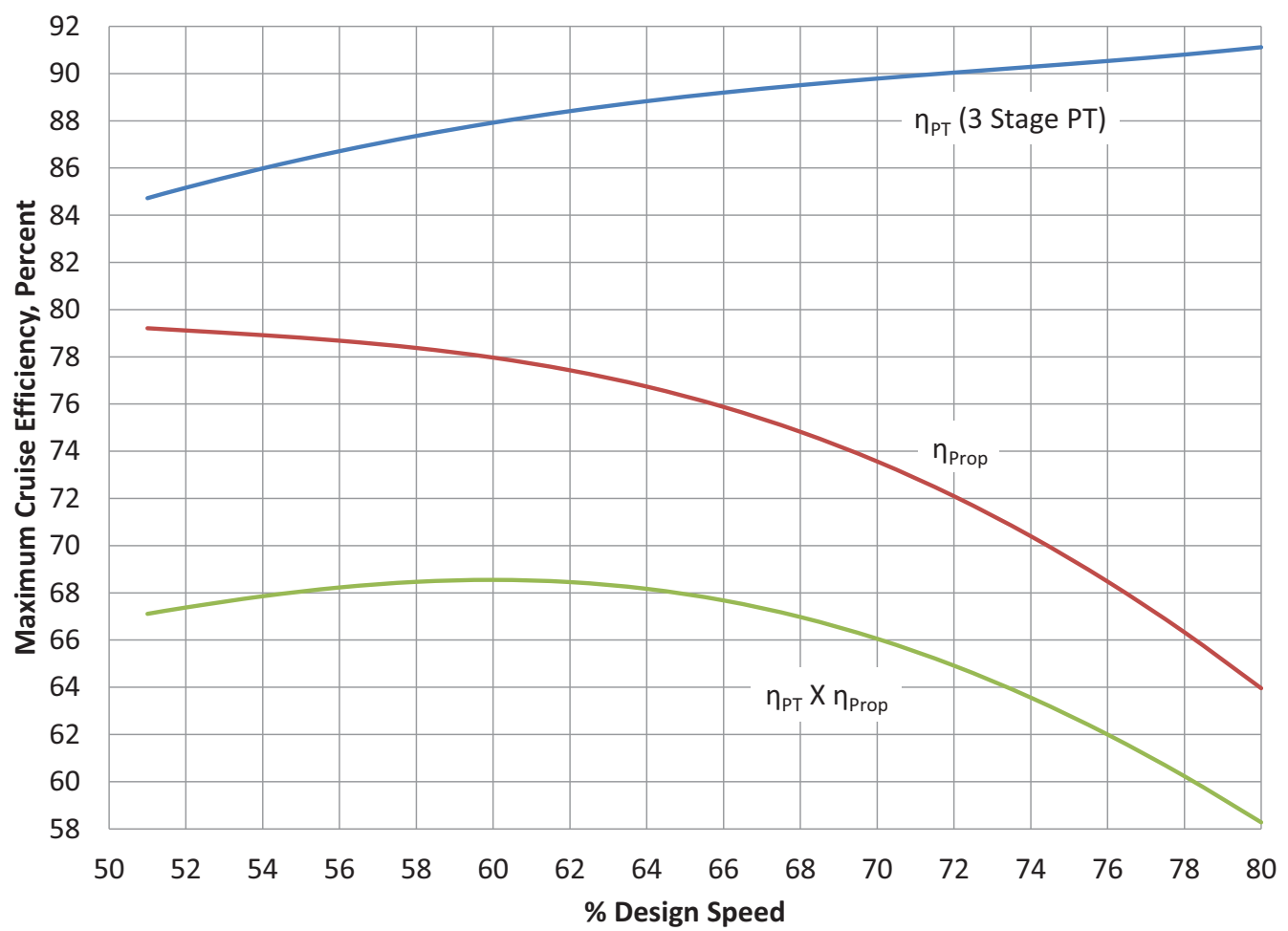

Figure 1. Prop/Rotor and PT Design Point Efficiency vs $\% N_{P T} \cdot{ }^{4}$

The opposing efficiency trends for the propeller and power turbine pose a challenge to the propulsion system design. One potential solution would be to decouple the speeds of the rotor/propeller and the power turbine across the flight regime by shifting in a multi-speed gearbox. In this solution, the aircraft would takeoff vertically and transition to forward flight then would shift to a better gear ratio for forward flight. By shifting, the power turbine could remain at a higher rotation speed for improved efficiency while the rotor/propeller speed is reduced. There are several concerns with this approach however. First, the shifting procedure is likely to be complicated as power must be maintained to the rotors during the entire process. Second, the multi-speed transmission will likely be heavier than a single speed gearbox and may require more maintenance over the life of the vehicle.

A second potential solution is to design the power turbine from the start to be robust to the large changes 
in speed required by the rotor/propeller and a single-speed gearbox. This solution has the advantages of a simpler transmission that will be less complex to operate, lower weight and easier to maintain. The major technical challenge comes from the aerodynamic design of the variable-speed power-turbine (VSPT). ${ }^{5}$ The traditional turbine design process as described by a number of authors focuses on designing at a single operating point. ${ }^{6,7}$ The VSPT concept does not fit well into the traditional single point design process because the wide range of operating conditions results in large incidence angles when far away from the design point. These affects have recently been studied at NASA Glenn Research Center (GRC) in both linear cascade experiments and computational fluid dynamics models. ${ }^{8-10}$ The knowledge gained from these investigations is ultimately needed to properly design the VSPT concept.

In order to better balance performance across multiple operating conditions, this study proposes a multidesign-point approach, based on a meanline analysis, to design the VSPT. The design problem is set up as an optimization with the goal of maximizing efficiency of all operating points while being constrained to match the power requirements from a mission analysis. The resulting meanline design will help assess the VSPT in comparison to the conventional turbine with a multi-speed gearbox for tiltrotor applications.

The following sections of this paper describe the initial development of the modeling and design optimization capability for a turbine required to operate extensively at two significantly different operating points. Section II describes the meanline analysis tool selected for this study as well as the optimization framework. Section III presents the design optimization approach taken in this study as well as the problem formulation. Preliminary results of the design optimization are then presented in Section IV followed by conclusions in Section V and future work in Section VI.

\section{Modeling Tools and Validation}

The focus of this research effort is the design optimization of a power turbine operating at multiple critical operating points at the meanline analysis level. Therefore, a meanline analysis tool capable of assessing this configuration needs to be selected in order to conduct the design optimization. While many meanline analysis tools exist, these tools are typically not well suited to modeling the multiple operating points as part of the design optimization. Furthermore, a tool with the flexibility to incorporate new knowledge gained from the cascade experiments and CFD analysis in the future is desired.

The Object-oriented Turbomachinery Analysis Code (OTAC), a meanline/streamline analysis code being developed at NASA Glenn Research Center, is well suited to this problem. ${ }^{11}$ As the name suggests, OTAC is being developed with an object-oriented structure to maximize the flexibility and utility of the code. OTAC is applicable to a wide range of turbomachines including both compressors and turbines of axial, mixed centrifugal and radial configurations.

A detailed discussion of the development and features of OTAC is provided by Jones ${ }^{11}$ with a short summary presented in this paper. OTAC has been developed by modifying the Numerical Propulsion System Simulation (NPSS) code. ${ }^{12}$ NPSS is a state-of-the-art, object-oriented propulsion modeling software package that was co-winner of the NASA Software of the Year Award in 2001. ${ }^{13}$ Changes to NPSS to create OTAC include adding new components (objects) for the turbomachinery flow segments, blade rows and transition segments as well as enhancements to the existing NPSS FlowStation object to represent the complete thermodynamic and velocity state of a given mass of fluid, including relative properties. Using NPSS as a base also enabled the easy implementation of its Newton-Raphson based solver for the solution of the meanline or streamline equations.

OTAC models of turbomachinery components are constructed by combining components as shown in the example in Figure 2. The figure depicts a model setup for a 3 streamline analysis of a single stage turbine. The figure is the same for the meanline analysis considered in this study except there would only be a single BladeSegment in each BladeRow. Additional stages can be easily included to create a multi-stage machine. An OTACstart component is used to set the inlet flow conditions which may then be passed to an Expander to create multiple streams if a streamline analysis is being conducted. Next, a BladeRow with one or more BladeSegment is defined; Transition objects are used used to account for area changes that occur in sections between blade rows. Rotating blade rows are attached to a shaft component which provides the rotation speed. Finally, a Reducer may be required to collapse multiple streams to a single stream to be passed to the FlowEnd.

Each blade row in the OTAC model solves the governing physics equations for the individual flow segments and overall blade using the NPSS solver. The solution of the governing equations also requires the calculation 


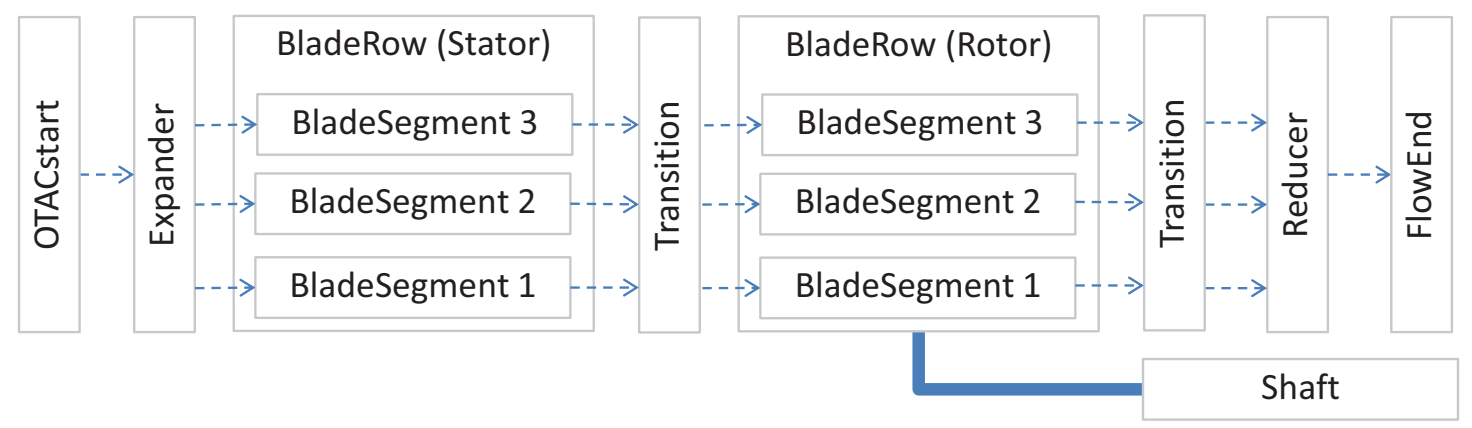

Figure 2. Sample OTAC Model Structure for 3 Streamlines.

of losses through the blade row. A number of different empirical models of these losses have been published for both compressors and turbines. To maintain the flexibility of OTAC, no single loss model has been selected. Instead, a loss model socket is included in the BladeSegment element allowing for the user to create or input their preferred loss model. To date at NASA GRC, the turbine loss models published by Ainley-Mathieson, ${ }^{14}$ Dunham-Came, ${ }^{15}$ and Kacker-Okapuu ${ }^{16}$ have been implemented in OTAC. While these three loss models are similar, the Kacker-Okapuu model is used in this study as it is the most representative of modern turbine designs. The Kacker-Okapuu loss model used in this study has been further enhanced by including the incidence model developed by Moustapha, Kacker and Tremblay. ${ }^{17}$

The solution to the governing equations and loss models in OTAC can be completed in two different modes. The design mode causes geometry to be calculated to meet specified performance. This typically includes determining the annulus dimensions as well as the entrance and exit flow angles for each blade row. In the second mode, off-design, the geometry specified from the design calculations is used to determine the resulting performance at other operating conditions. Both of these modes are important for this analysis as the VSPT must be designed at an operating point then evaluated over its entire operating range to determine the best design.

As OTAC is a relatively new analysis tool, it is important to validate its performance before using the tool as part of this design optimization study. First, OTAC was validated by comparing its simulation output to the results produced by similar meanline analysis tools for the same inputs. Second, OTAC has been validated for turbines by comparing results to sample output from the Ainley-Mathieson and KackerOkapuu loss model papers. This comparison provides a check of not only the governing equations in the model but also the specific implementation of each loss model. Finally, validation of OTAC and the selected loss models for turbines can be achieved by recreating the classic Smith chart which shows the correlation of flow coefficient, loading coefficient and efficiency for a single stage at its design condition. ${ }^{18}$ Figure 3 shows the Smith chart that was created in OTAC using the Ainley-Mathieson loss model.

In addition to using OTAC for the meanline analysis, a second software package is used in this study to facilitate the design optimization. OTAC does not include a built in optimizer and rather than develop a unique implementation of a selected optimization algorithm, a general Multidisciplinary Design, Analysis and Optimization (MDAO) frameworking tool can be used to simplify this task. NASA is currently supporting the development of one such tool, OpenMDAO. OpenMDAO is an open source MDAO frameworking environment that allows for analysis from different disciplines and written in different programming languages to be integrated in complex ways to execute overall simulations and optimization. ${ }^{19}$ OpenMDAO is easily applied to this problem by building a wrapper for the OTAC model which allows OpenMDAO to access the model inputs, outputs and execution function. With this wrapper, OpenMDAO can control the execution of OTAC through the use of any one of many standard optimization algorithms which are included in the framework and are easy to apply to this problem. 


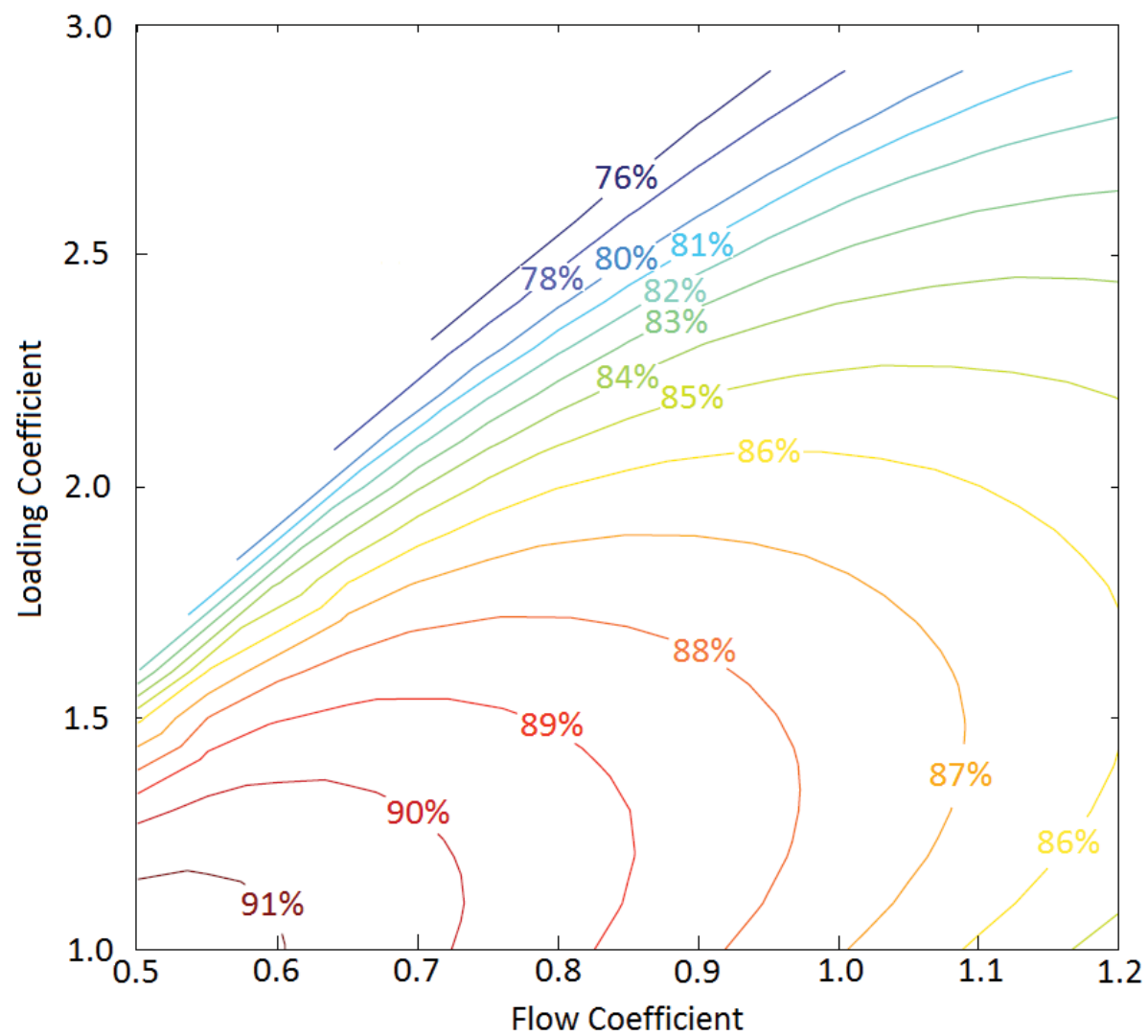

Figure 3. Smith Chart Produced with Ainley-Mathieson Loss Model.

\section{Design Approach}

\section{VSPT Model}

The OTAC meanline analysis tool described in the previous section was used to model a 4-stage VSPT model. Each stage in the OTAC model contains the following elements in this order: vane, transition duct, rotor, transition duct. A cross-section view of the baseline VSPT design is given in Figure 4. The dotted line shows the meanline which is modeled in OTAC.

The VSPT was designed to meet performance requirements at two conditions: Vertical Takeoff and Cruise. For each condition, incoming flow conditions as well as speed and power requirements are described in Table 1. The cruise condition was selected as the aerodynamic design point for the turbine, which means that many of the design variables are specified at the cruise condition. While cruise is the official design point in the OTAC model, the takeoff operating point is just as critical to assessing the VSPT design. The performance results produced at both of these operating points are considered simultaneously by the design optimization algorithm creating a multi-design point solution.

Table 1. Cruise and Takeoff Operating Conditions.

\begin{tabular}{|l|c|c|}
\hline Operating Condition Parameter & Cruise Value & Takeoff Value \\
\hline Mass Flow, lbm/sec & 12.2 & 22.7 \\
\hline Total Temperature, R & 1812 & 2204 \\
\hline Total Pressure, PSI & 26.8 & 58.0 \\
\hline Flow Angle, deg & 0 & 0 \\
\hline Shaft Speed, RPM & 8100 & 15000 \\
\hline
\end{tabular}




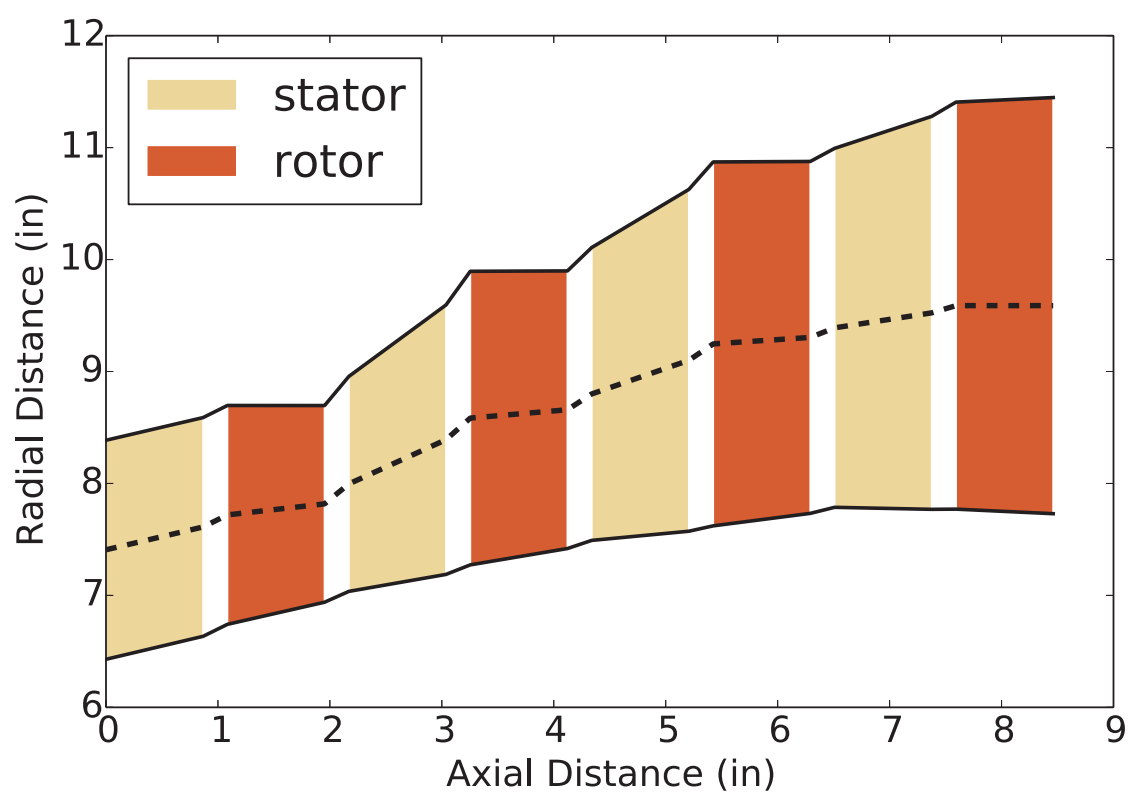

Figure 4. Initial VSPT Geometry.

While the OTAC design point for the VSPT was selected at the cruise operating condition, it is important to note that this does not imply that the incidence angle for each blade row is set to zero at cruise. Incidence angles for each blade row were given as design variables for the optimizer to vary in order to balance performance between takeoff and cruise. This design philosophy appears to be different than previous VSPT meanline studies. ${ }^{20,21}$ In those studies, the VSPT design was usually completed at an intermediate operating condition that was between cruise and takeoff where the incidence was zero on all blades.

\section{Problem Formulation}

As mentioned in the introduction, the objective of this study is to investigate the design characteristics of a turbine capable of efficiently operating at two vastly different operating points. This section lays out the detailed optimization problem formulation that is used to achieve this goal. The problem formulation includes identifying three critical elements for the design optimization: the objective function, design variables, and constraints. These three elements are defined for this VSPT study in Table 2 and discussed in the following paragraphs.

The objective function states the quantity that the optimizer is trying to maximize or minimize. For this study, a simple objective function was selected which focuses on maximizing the VSPT efficiency at both the cruise and takeoff operating points. The objective for this study is therefore to maximize the combined efficiency as stated at the top of the table. In this equation, the $\lambda$ parameters are weighting coefficients which set the importance of each operating point in the objective function. Initially, the weighting factors have been set such that the two operating points are of equal importance. While this weighting was selected for the current study, the weightings could have easily been set to other values such as the amount of time a typical flight would spend at that operating point.

The second aspect of the problem formulation is identifying the design variables that will be controlled in the optimization and their appropriate ranges. Forty-six total design variables were identified for this preliminary study and are summarized in Table 2. Further details for the individual design variables and their allowable ranges are provided in Table 3 in the Appendix. The lower and upper limits for each variable were set as a range around the initial VSPT model and may be adjusted in future studies. The design variables include the exit Mach number and mean radius from each blade row and transition section. The design incidence for each blade row as well as the exit flow angle from the vanes are also included as design 
Table 2. Small satellite design problem formulation

\begin{tabular}{|c|c|c|c|}
\hline & Variable/Function & Description & Quantity \\
\hline maximize & $\lambda_{c r} \eta_{c r}+\lambda_{t o} \eta_{t o}$ & Combined efficiency & \\
\hline \multirow[t]{10}{*}{ with respect to } & $s$ & Percent of total cruise work extracted by rotor & 3 \\
\hline & $M_{\text {vane }}$ & Vane exit Mach number & 4 \\
\hline & $M_{\text {rotor }}$ & Rotor exit Mach number & 4 \\
\hline & $M_{\text {transition }}$ & Transition section exit Mach number & 7 \\
\hline & $r_{\text {vane }}$ & Vane exit mean radius & 4 \\
\hline & $r_{\text {rotor }}$ & Rotor exit mean radius & 4 \\
\hline & $r_{\text {transition }}$ & Transition section exit mean radius & 8 \\
\hline & $i$ & Design incidence angle & 8 \\
\hline & $\alpha$ & Vane exit flow angle & 4 \\
\hline & & Total & 46 \\
\hline \multirow[t]{6}{*}{ subject to } & $A N_{\text {to }}^{2} \leq 55 \times 10^{9}$ & Mechanical stress constraint & 1 \\
\hline & $P_{c r}=2700 h p$ & Cruise power constraint & 1 \\
\hline & $P_{t o}=5290 h p$ & Takeoff power constraint & 1 \\
\hline & $\left|\alpha_{\text {rotor } 4}\right| \leq 20^{\circ}$ & Cruise exit swirl angle constraint & 1 \\
\hline & $|\gamma| \leq 15^{\circ}$ & Hub hade angle constraint & 16 \\
\hline & & Total & 20 \\
\hline
\end{tabular}

variables. Lastly, the percentage of the total required cruise work extracted by each of the first three rotors are design variables. The work extracted by the fourth rotor is not a design variable but is calculated based on the percentages of the first three rotors.

Finally, the problem formulation states the constraints that must be satisfied during the design optimization. The constraints identified are expressed in the last section of Table 2. The first constraint on $A N_{T O}^{2}$ is included in the design optimization to account for mechanical stress limits on the last rotor. The second and third constraints are used to ensure that the necessary power is produced by the turbine at both operating conditions. Next, the cruise exit swirl from the last rotor is constrained to minimize the loss in thrust in the downstream nozzle. Finally, the last constraint is used to represent 16 total constraints. These constraints limit the hub hade angle defined as the angle of the hub wall with the axial direction.

\section{Optimization Process}

The problem formulation with the objective function, design variables and constraints establishes the details of the design problem. The last component of the design optimization approach is to select and apply an optimization algorithm. For this preliminary work, the SNOPT ${ }^{22}$ algorithm developed at Stanford University was selected. SNOPT is a sequential quadratic programming method that is well suited for largescale constrained optimization problems. In order to use the SNOPT method, gradients of the objective function and constraints need to be determined with respect to the design variables. OTAC does not provide analytic gradients, so finite difference approximations were used. Despite the relative quickness of evaluating the OTAC model (about 10 seconds per design), the calculation of each finite difference step for the 46 design variables at each iteration results in a significant iteration computation time (on the order of 10 minutes per iteration) and overall execution time.

Considerable effort was spent during the initial formulation of this design optimization determining appropriate values for the SNOPT settings. The major and minor feasibility tolerances were each set to values of $1 \mathrm{E}-6$ while the optimality tolerance was set to $1 \mathrm{E}-4$. Furthermore, a relative step size of $1 \mathrm{E}-3$ was used for all finite difference steps. This step size is fairly large, and somewhat limits the accuracy of the gradients that can be calculated. However, numerical convergence difficulties prevented any smaller step size from yielding non-zero gradients. This phenomenon is a result of the step falling within the tolerance limits 
of the Newton-Raphson solver used by OTAC.

\section{Preliminary Optimization Results}

The design optimization approach described in the previous section was followed to obtain a preliminary design optimization of the VSPT concept. The starting point for the optimization was the initial design shown in Figure 4 and listed in the "Initial Values" column of Table 3 located in the Appendix. From this starting point, the SNOPT algorithm worked to find an optimal solution that met all of the constraints. The iteration history for the cruise and takeoff efficiencies (which combine to form the objective function) is shown in Figure 5. The figure indicates that after some large variations in the first few iterations, the optimizer found a design that improved both efficiencies by more than $1 \%$ from the initial design. The iteration was continued beyond these initial iterations as the optimizer was working to better meet the problem constraints.

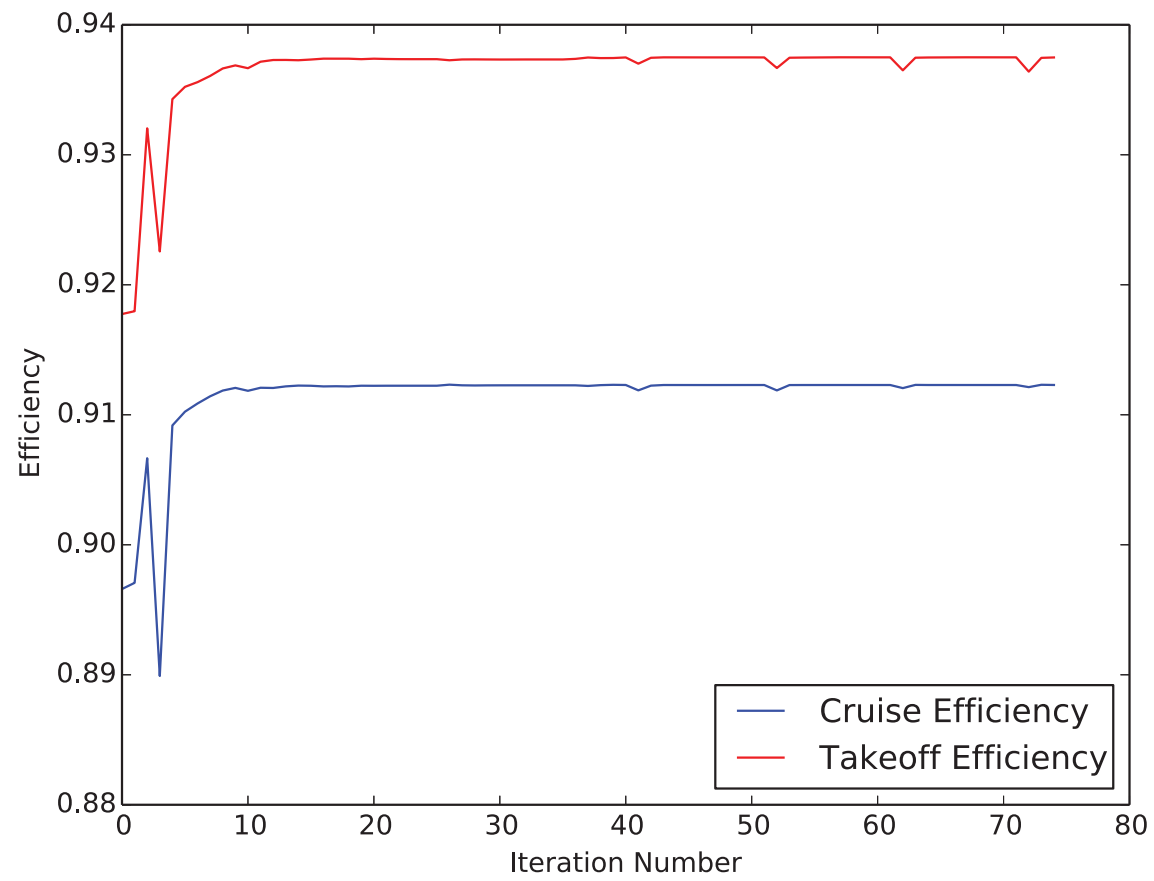

Figure 5. Optimization History of Cruise and Takeoff Efficiencies.

The initial and final values for the objective function and constraint values are given in the Appendix in Table 4. This table shows that the initial design was infeasible as many of the hub hade angles were greater than 15 degrees. Furthermore, the initial takeoff power did not closely match the required takeoff power. However, the design found by the optimizer fell within tolerance on the hub hade angle constraints and improved on takeoff power constraint. Further improvement on meeting these constraints once the objective function plateaued was hampered by the poor gradients produced by the finite difference steps.

While Figure 5 and Table 4 show that the optimizer improved upon the initial design, it is important to critically review the features of the preliminary optimal design to assess what characteristics were deemed beneficial for the VSPT design as well as areas where the meanline model may need further improvement. To start, the final turbine annulus geometry determined by the optimizer is shown in Figure 6 . This annulus geometry looks significantly different from the initial design given in Figure 4 as the outer annulus geometry tip) of the final design takes on a sawtooth pattern. This feature is a result of the optimizer finding improved performance by increasing the blade inlet Mach number and decreasing the blade exit Mach number. The blade inlet and exit Mach numbers are both influential terms in the Kacker-Okapuu loss model as they directly affect the profile, shock and trailing edge thickness loss components. 


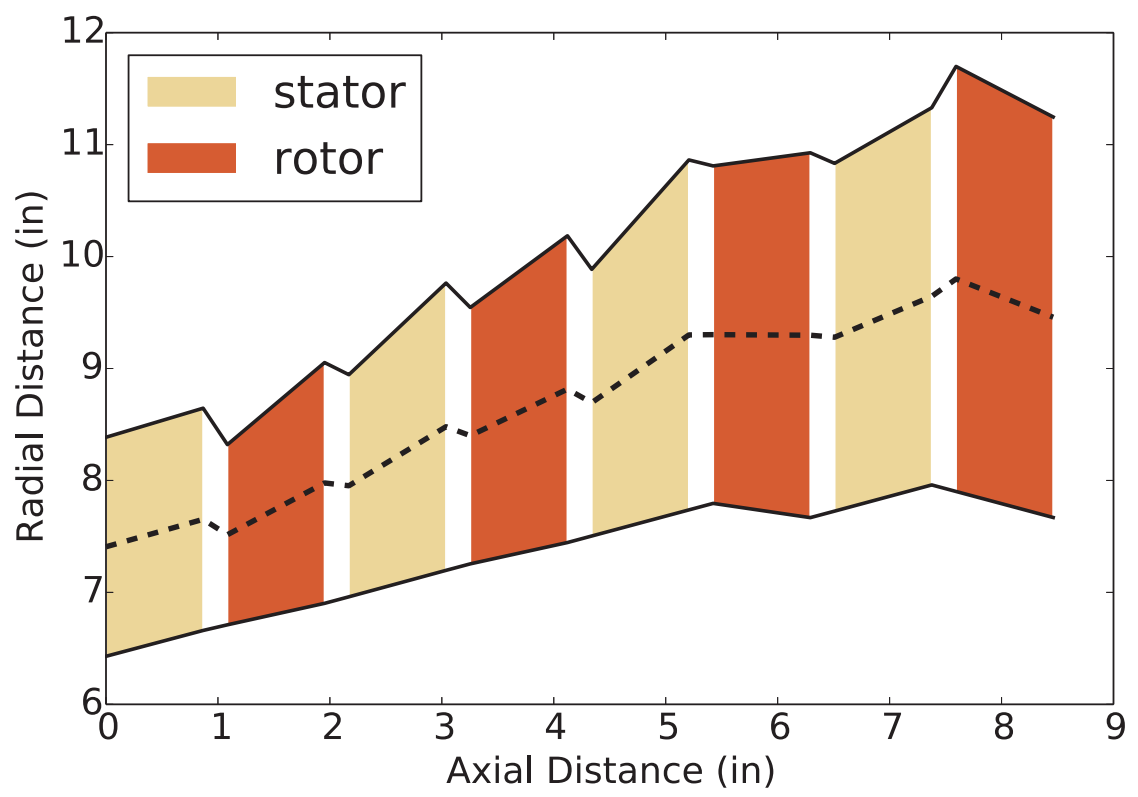

Figure 6. VSPT Geometry Resulting from Design Optimization.

While the optimizer identified the sawtooth outer annulus geometry as an optimal design, it is highly unlikely this would be a good design if manufactured and tested. Even if the sharp corners were smoothed out, the large changes in flow direction would likely result in flow separation near the blade tips and decrease overall performance. These flow features are not captured by the simple meanline analysis and highlight the need for additional higher fidelity models to be integrated into the design process to capture these more subtle flow effects.

In addition to looking at the annulus geometry for insights to the ideal VSPT design, reviewing the changes made during the design optimization to the design variables is also beneficial. The optimal values found for all the design variables are listed in the last column of Table 3 in the Appendix. Some of the interesting trends observed in this data are presented in the following figures.

One of the interesting results of the preliminary design optimization study relates the the work split across the stages. The initial design had the highest percentage of the work extracted by the second and third stages with the first and last stages extracting less work as shown in Figure 7. The design optimization process determined that a more equal work split across the rotors was beneficial to the overall performance and constraints. The first and last rotors increased their work extraction while the middle two stages reduced their output.

Another interesting result obtained from this optimization is that the design incidence at cruise should be set to a non-zero value, but at a different value for each blade row. The final result shows that the best total efficiency is achieved when there is positive incidence on each blade row. The incidence angles selected for each blade row do not seem to be random however and follow a distinct trend as shown in Figure 8. The design incidence is near zero for the first vane and increases over the following blade rows until it reaches the maximum of 15 degrees for the second stage rotor. The incidence plateaued at 15 degrees for the 2 nd and 3rd stages, but then dropped back down for the 4th stage. The problem formulation included a constraint limiting incidence to no more than 15 degrees, which caused this plateau in the design. This constraint was an assumption in this preliminary analysis. These results indicate that higher incidences might be beneficial to the overall VSPT efficiency and that this assumed constraint value may have been restrictive.

There are several non-dimensional parameters that are typically used to characterize the turbine design. These parameters include the degree of reaction (static-to-static), loading coefficient and flow coefficient. For clarity, the definitions of these parameters for this study are provided in Equations 1 through 3. The 


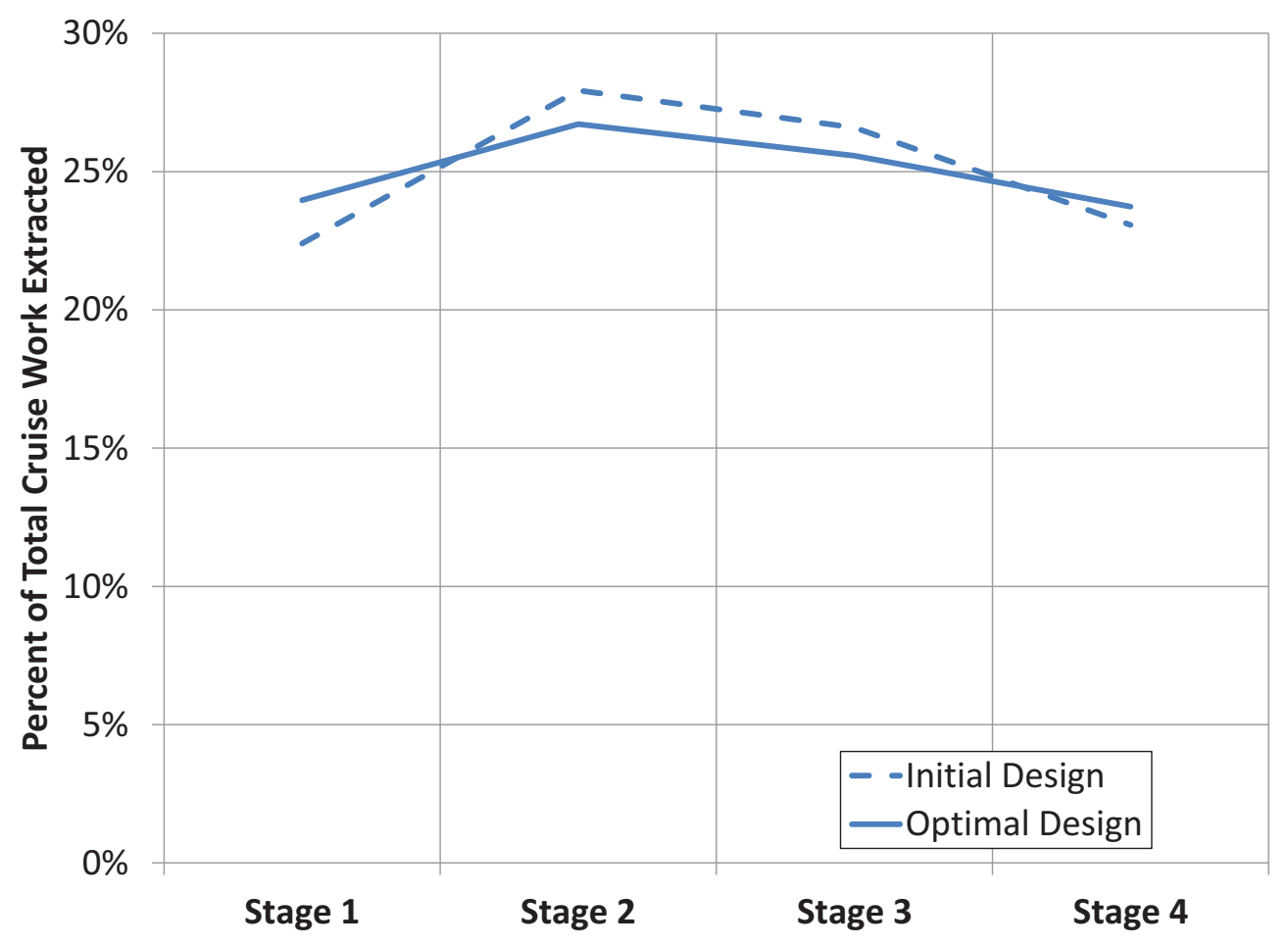

Figure 7. Comparison of Initial and Optimal Stage Work Splits at the Cruise Operating Point.

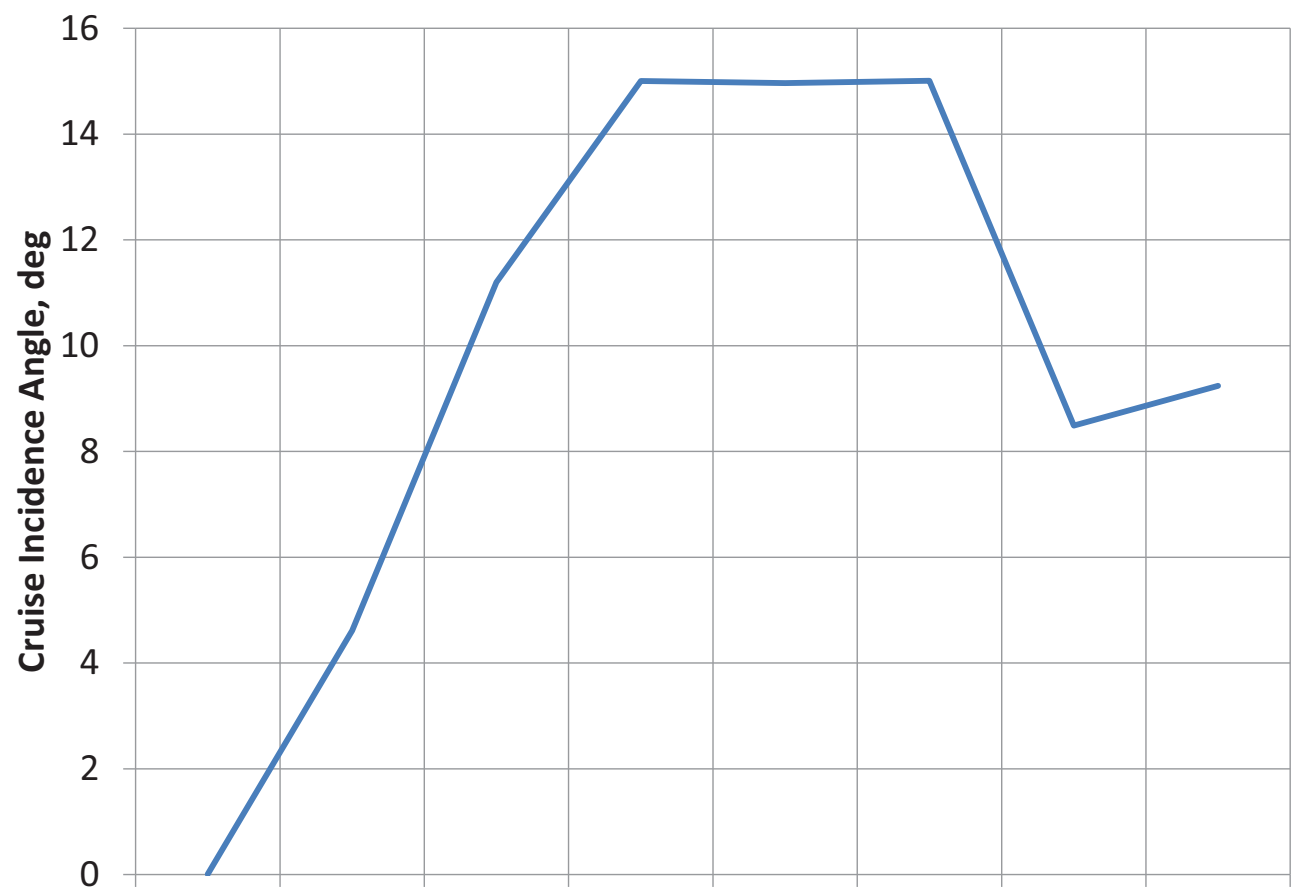

Vane 1 Rotor 1 Vane 2 Rotor 2 Vane 3 Rotor 3 Vane 4 Rotor 4

Figure 8. Optimal Incidence at the Cruise Operating Point. 
results for each of these parameters at both cruise and takeoff operating conditions are given in Appendix Table 5.

$$
\begin{gathered}
{ }^{\circ} R=\frac{\Delta h_{\text {rotor }}}{\Delta h_{\text {stage }}} \\
\psi=\frac{\Delta h_{t}}{(\omega r)^{2}}=\frac{\Delta h_{t}}{U^{2}} \\
\phi=\frac{V_{z}}{\omega r}=\frac{V_{z}}{U}
\end{gathered}
$$

First, for the degree of reaction the baseline VSPT design had a value at cruise of around 0.52 for each of the four stages as shown in Figure 9. For takeoff, the baseline design has the degree of reaction falling across each stage. However, the optimal design completely changes these trends. At both cruise and takeoff, the optimal degree of reaction goes up as you move from the front to aft stages.

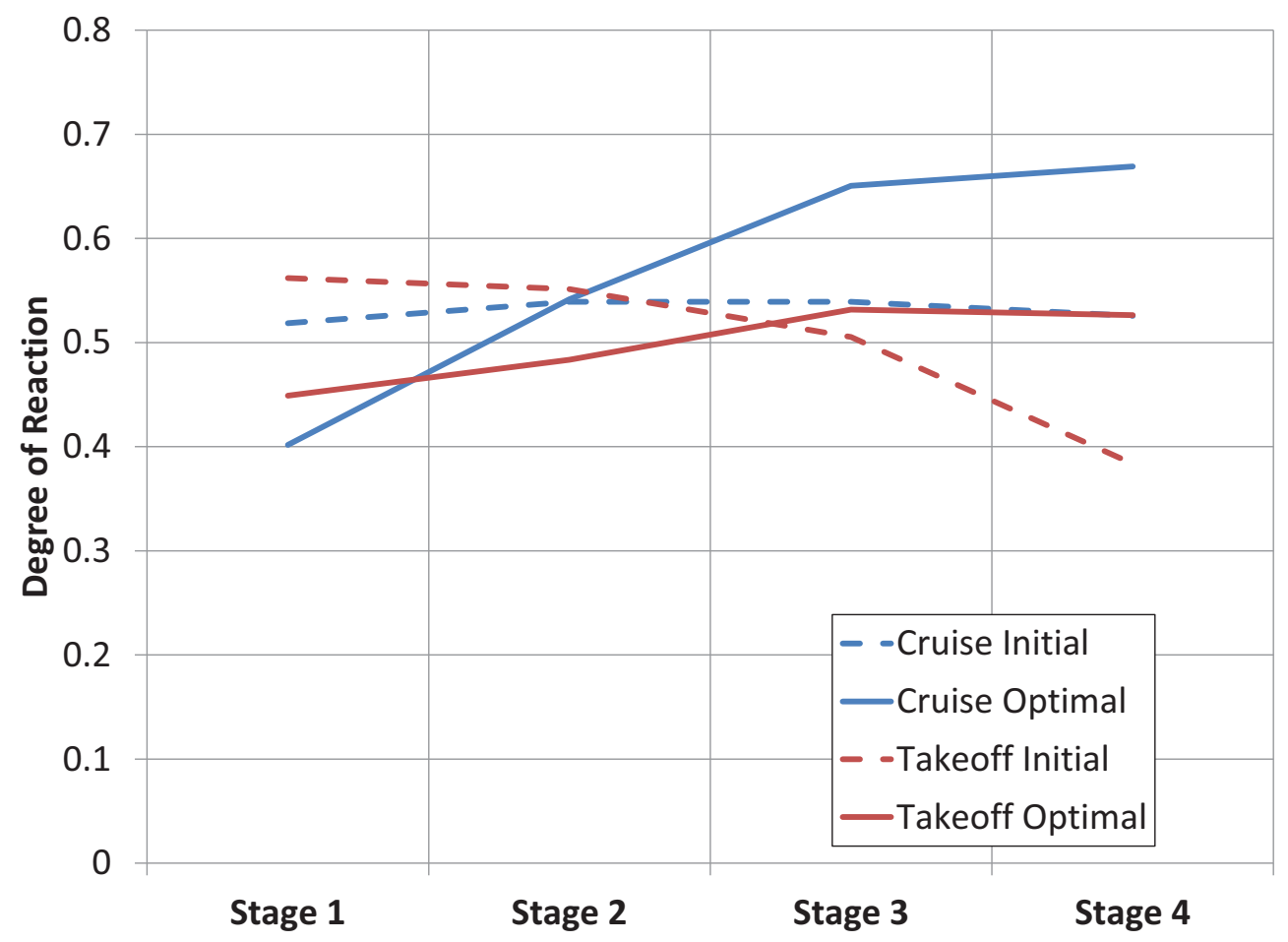

Figure 9. Comparison of Initial and Optimal Stage Reactions at both Cruise and Takeoff Operating Points.

For the loading coefficient, the design optimization process resulted in less significant changes to the initial values as shown in Figure 10. The overall negative trend for the loading coefficient from front to aft stages was maintained in the optimal design. The optimal flow coefficient trend, however, appears to be different than that assumed in the initial design. The initial design at both cruise and takeoff operating points featured a shallow bucket shape with the first and last stages having slightly higher flow coefficients than the middle two stages. The optimizer determined that for best performance within the constraints the flow coefficients should generally follow a negative trend from front to aft stages.

\section{Conclusions}

NASA's Rotary Wing Project is researching and developing technologies which will improve future rotorcraft. One of the technologies currently of interest is the variable-speed power-turbine (VSPT) which may provide better system performance for tiltrotor aircraft over a conventional power turbine and multi-speed 


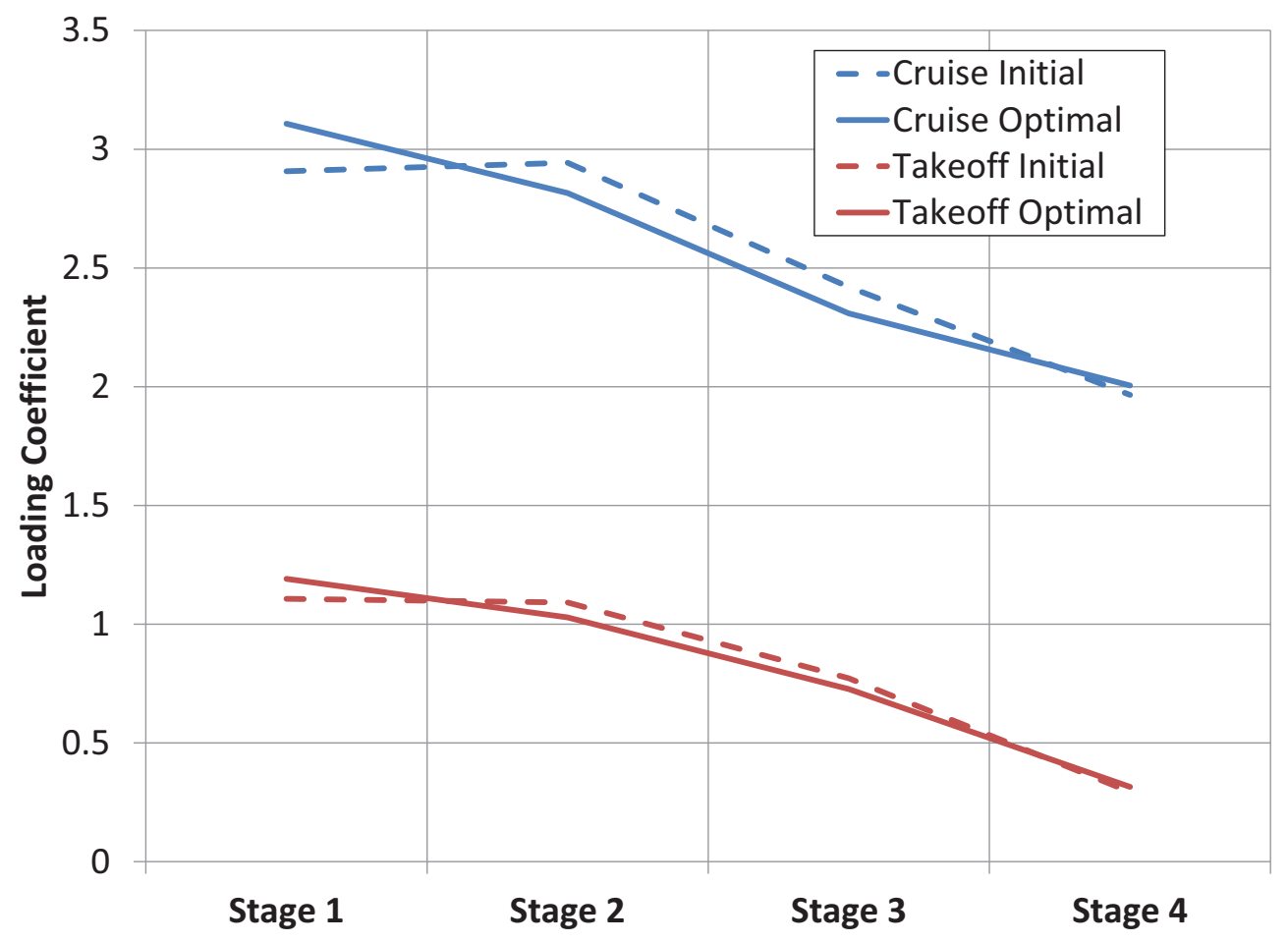

Figure 10. Comparison of Initial and Optimal Loading Coefficients at both Cruise and Takeoff Operating Points.

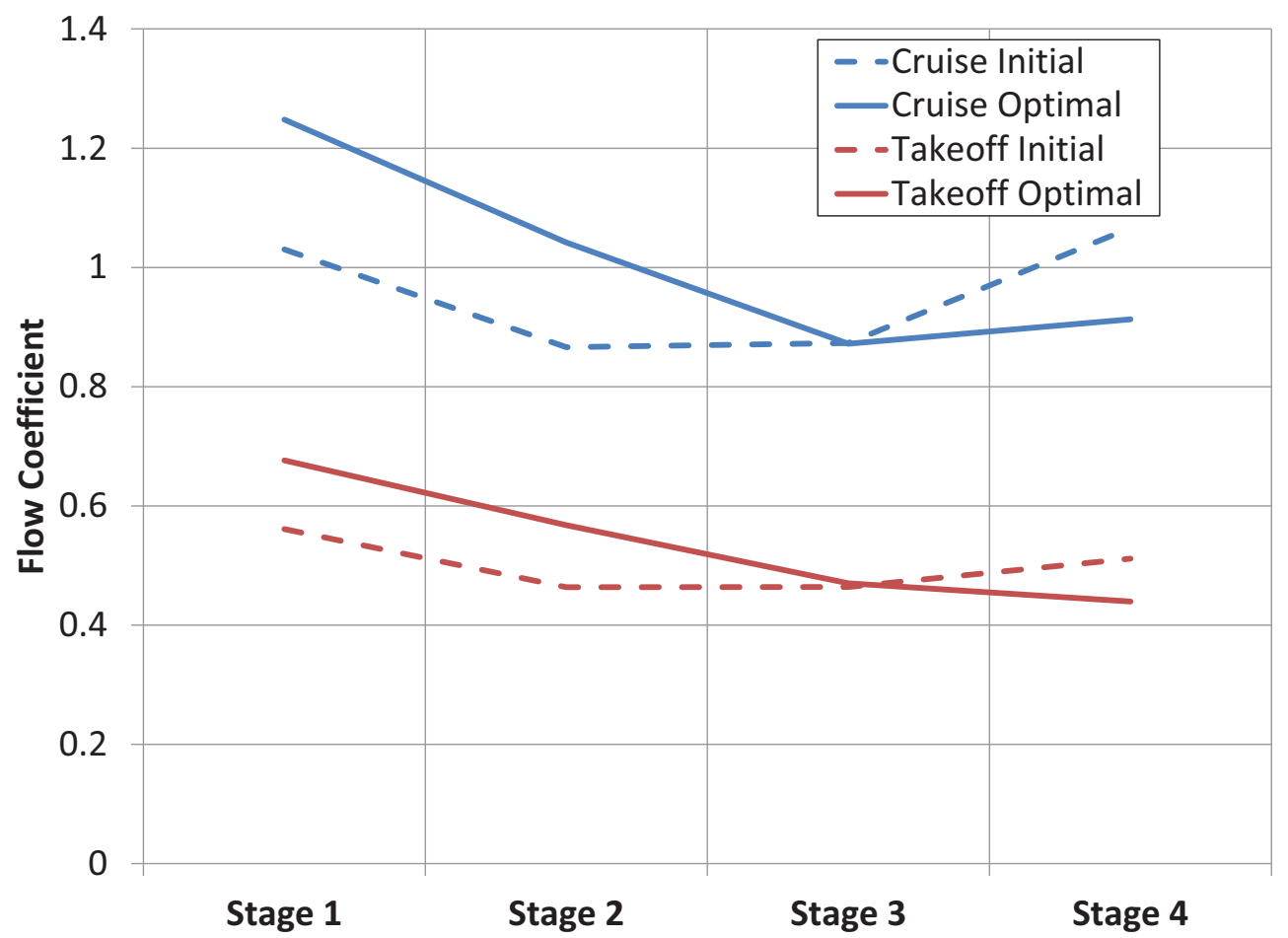

Figure 11. Comparison of Initial and Optimal Flow Coefficients at both Cruise and Takeoff Operating Points. 
gearbox propulsion architecture. The focus of this study was to develop a meanline design optimization capability for a multi-operating point turbine such as the VSPT and generate preliminary results which provide insight into the desired design characteristics for this type of turbine.

The results from this study show that an improved design can be achieved through the application of a multi-point design optimization approach. The resulting optimum design has several distinct features compared to the initial design. First, the overall performance is improved by having a positive incidence on all blade rows at the low speed cruise condition. The incidence angles are unique for each blade row but follow a parabolic trend with the front and aft blade rows having lower incidence while the middle blade rows have incidence near the maximum 15 degrees allowed.

Additionally, the trends for the work split between stages, reaction and flow coefficient of the preliminary optimum design differed from the initial VSPT design characteristics. The work split of the optimum has a more even distribution among the stages. For the reaction, the initial design with approximately constant reaction during cruise was changed to have a lower reaction on the first stages with higher reactions on the later stages. The change in cruise reaction also impacted reaction values at the takeoff operating point resulting in a trend with an opposite slope. Overall, these preliminary results show that a multi-operating point design optimization approach may be able to find a robust solution that can be efficiently operated at two extremely different speeds.

The optimal design also identified a number of questions and issues that will need to be addressed moving forward with this research. First, it was identified that the optimizer was driving to an unrealistic outer annulus geometry with a jagged sawtooth shape. This occurred because the optimizer took advantage of a weakness in the semi-empirical loss models used which depended strongly on the ratio of inlet to exit mach number. This highlights the need to incorporate higher fidelity analyses into the design process to account for more subtle flow phenomenon. Additionally, the loss models are likely being extrapolated by some of the extreme cruise and takeoff incidence angles that are experienced by the VSPT concept.

The design optimization approach taken in this study also identified some areas for further investigation for the design optimization approach itself. The gradient based optimization that was used required the calculation of numerous derivatives using finite difference steps. These calculations were time consuming and often resulted in poor gradient approximations. The gradient approximations were limited by the larger step size required as a result of the convergence tolerance of the internal solvers of the Object-oriened Turbomachinery Analysis Code (OTAC) meanline analysis tool. Too small a step size would result in the calculation of a zero gradient for all parameters as the changes at that step size were within the tolerance of the meanline analysis solver. In addition, the use of finite diffference gradients requires one function evaluation for each new design variable. This introduces a significant computational cost for each new design variable. Applying analytic adjoint gradient methods, commonly used in aerodynamics shape optimization, would help solve both the accuracy and computational cost challenges of finite differencing.

\section{Future Work}

While this study has developed a preliminary design optimization approach and initial results for a VSPT, there are several areas that need to be improved upon in future work. The objective function developed for this study was generic in terms of the importance of the two critical operating points. An equal weighting of the efficiencies was selected for this study, but a more appropriate weight based on the amount of time spent at that operating point may be desired. Alternately, the two efficiencies could be considered as independent objectives and a multi-objective optimization method could be used to develop a Pareto frontier. Other metrics like turbine weight or engine specific fuel consumption may also be considered as part of the objective function. Finally, a completely different optimization algorithm could be selected. The gradient based optimization used in this study will only find a local optimum based on its initial starting point and is limited by the finite difference gradient calculations. Global optimization approaches such as genetic algorithms, particle swarm and efficient-global optimization could be applied to improve the probability of finding the overall best solution. 


\section{Appendix}

Table 3. Design Variables with Ranges, Initial Values and Final Values.

\begin{tabular}{|c|c|c|c|c|}
\hline Design Variable Name & Lower Limit & Upper Limit & Initial Value & Optimal Value \\
\hline Rotor 1 Percent of Total Cruise Power & 0.2000 & 0.2500 & 0.2240 & 0.2397 \\
\hline Rotor 2 Percent of Total Cruise Power & 0.2500 & 0.3000 & 0.2793 & 0.2672 \\
\hline Rotor 3 Percent of Total Cruise Power & 0.2300 & 0.2800 & 0.2659 & 0.2558 \\
\hline Vane 1 Exit Mach Number & 0.5500 & 0.6500 & 0.6170 & 0.6221 \\
\hline Rotor 1 Exit Mach Number & 0.4500 & 0.5500 & 0.4720 & 0.4530 \\
\hline Vane 2 Exit Mach Number & 0.6500 & 0.7500 & 0.7380 & 0.6500 \\
\hline Rotor 2 Exit Mach Number & 0.4500 & 0.5500 & 0.4810 & 0.4502 \\
\hline Vane 3 Exit Mach Number & 0.6500 & 0.7500 & 0.7470 & 0.6500 \\
\hline Rotor 3 Exit Mach Number & 0.4500 & 0.5500 & 0.4800 & 0.4636 \\
\hline Vane 4 Exit Mach Number & 0.6500 & 0.7500 & 0.7660 & 0.7500 \\
\hline Rotor 4 Exit Mach Number & 0.5000 & 0.6000 & 0.5650 & 0.5929 \\
\hline Transition 1a Exit Mach Number & 0.5500 & 0.6500 & 0.6070 & 0.6500 \\
\hline Transition 1b Exit Mach Number & 0.4000 & 0.4800 & 0.4300 & 0.4800 \\
\hline Transition 2a Exit Mach Number & 0.6500 & 0.7500 & 0.7060 & 0.6792 \\
\hline Transition 2b Exit Mach Number & 0.4000 & 0.5000 & 0.4550 & 0.5000 \\
\hline Transition 3a Exit Mach Number & 0.6500 & 0.7500 & 0.7210 & 0.6561 \\
\hline Transition 3b Exit Mach Number & 0.4000 & 0.5000 & 0.4660 & 0.4999 \\
\hline Transition 4a Exit Mach Number & 0.7000 & 0.7700 & 0.7470 & 0.7000 \\
\hline Vane 1 Exit Mean Radius & 7.5000 & 8.0000 & 7.6115 & 7.6323 \\
\hline Transition 1a Exit Mean Radius & 7.5000 & 8.0000 & 7.7190 & 7.5784 \\
\hline Rotor 1 Exit Mean Radius & 7.5000 & 8.2000 & 7.8175 & 7.9648 \\
\hline Transition 1b Exit Mean Radius & 7.7000 & 8.3000 & 7.9960 & 7.9342 \\
\hline Vane 2 Exit Mean Radius & 8.0000 & 8.5000 & 8.3910 & 8.4942 \\
\hline Transition 2a Exit Mean Radius & 8.4000 & 8.8000 & 8.5840 & 8.4000 \\
\hline Rotor 2 Exit Mean Radius & 8.5000 & 8.9000 & 8.6585 & 8.8416 \\
\hline Transition 2b Exit Mean Radius & 8.6000 & 9.0000 & 8.7995 & 8.7113 \\
\hline Vane 3 Exit Mean Radius & 8.9000 & 9.3000 & 9.1000 & 9.3000 \\
\hline Transition 3a Exit Mean Radius & 9.0000 & 9.5000 & 9.2465 & 9.3026 \\
\hline Rotor 3 Exit Mean Radius & 9.1000 & 9.5000 & 9.3045 & 9.3240 \\
\hline Transition 3b Exit Mean Radius & 9.2000 & 9.6000 & 9.3900 & 9.2549 \\
\hline Vane 4 Exit Mean Radius & 9.3000 & 9.7000 & 9.5240 & 9.6446 \\
\hline Transition 4a Exit Mean Radius & 9.4000 & 9.8000 & 9.5885 & 9.8000 \\
\hline Rotor 4 Exit Mean Radius & 9.4000 & 9.8000 & 9.5885 & 9.4549 \\
\hline Transition 4b Exit Mean Radius & 9.4000 & 9.8000 & 9.5885 & 9.4549 \\
\hline Vane 1 Design Incidence & 0.0000 & 15.0000 & 0.0000 & 0.0102 \\
\hline Rotor 1 Design Incidence & 0.0000 & 15.0000 & 0.0000 & 4.6162 \\
\hline Vane 2 Design Incidence & 0.0000 & 15.0000 & 0.0000 & 11.1988 \\
\hline Rotor 2 Design Incidence & 0.0000 & 15.0000 & 0.0000 & 15.0071 \\
\hline Vane 3 Design Incidence & 0.0000 & 15.0000 & 0.0000 & 14.9663 \\
\hline Rotor 3 Design Incidence & 0.0000 & 15.0000 & 0.0000 & 15.0115 \\
\hline Vane 4 Design Incidence & 0.0000 & 15.0000 & 0.0000 & 8.4894 \\
\hline Rotor 4 Design Incidence & 0.0000 & 15.0000 & 0.0000 & 9.2430 \\
\hline Vane 1 Exit Angle & 55.0000 & 65.0000 & 61.9800 & 62.0025 \\
\hline Vane 2 Exit Angle & 55.0000 & 68.0000 & 64.5500 & 64.6048 \\
\hline Vane 3 Exit Angle & 55.0000 & 68.0000 & 62.0500 & 62.0989 \\
\hline Vane 4 Exit Angle & 50.0000 & 60.0000 & 54.0600 & 54.1439 \\
\hline
\end{tabular}


Table 4. Initial and Final Objective and Constraint Values.

\begin{tabular}{|l|c|c|}
\hline Parameter & Initial Value & Optimal Value \\
\hline Cruise Efficiency & 0.8966 & 0.9123 \\
\hline Takeoff Efficiency & 0.9175 & 0.9375 \\
\hline Takeoff Power, HP & 5265.1599 & 5283.7902 \\
\hline Takeoff $A N^{2}$, in $\times$ RPM ${ }^{2}$ & $5.0391 \mathrm{E}+10$ & $4.7669 \mathrm{E}+10$ \\
\hline Cruise Exit Swirl, deg & -17.8885 & -20.0000 \\
\hline Vane 1 Hub Hade Angle, deg & 13.3104 & 14.9993 \\
\hline Transition 1a Hub Hade Angle, deg & 26.2443 & 14.9228 \\
\hline Rotor 1 Hub Hade Angle, deg & 12.8351 & 13.0123 \\
\hline Transition 1b Hub Hade Angle, deg & 24.0058 & 15.0216 \\
\hline Vane 2 Hub Hade Angle, deg & 9.9111 & 15.0048 \\
\hline Transition 2a Hub Hade Angle, deg & 21.4650 & 15.0031 \\
\hline Rotor 2 Hub Hade Angle, deg & 9.5357 & 10.9859 \\
\hline Transition 2b Hub Hade Angle, deg & 18.5343 & 14.9753 \\
\hline Vane 3 Hub Hade Angle, deg & 5.3931 & 15.0015 \\
\hline Transition 3a Hub Hade Angle, deg & 12.4615 & 15.0045 \\
\hline Rotor 3 Hub Hade Angle, deg & 7.3228 & -7.5319 \\
\hline Transition 3b Hub Hade Angle, deg & 13.9884 & 14.9943 \\
\hline Vane 4 Hub Hade Angle, deg & -1.1807 & 15.0000 \\
\hline Transition 4a Hub Hade Angle, deg & 0.4432 & -14.9363 \\
\hline Rotor 4 Hub Hade Angle, deg & -2.6851 & -14.9994 \\
\hline Transition 4b Hub Hade Angle, deg & 0.0000 & 0.0000 \\
\hline
\end{tabular}


Table 5. Characteristics of the VSPT at Cruise and Takeoff.

\begin{tabular}{|c|c|c|c|c|}
\hline Parameter & Cruise Initial & Cruise Optimal & Takeoff Initial & Takeoff Optimal \\
\hline Stage 1 Reaction & 0.5187 & 0.4017 & 0.5619 & 0.4491 \\
\hline Stage 2 Reaction & 0.5393 & 0.5416 & 0.5514 & 0.4835 \\
\hline Stage 3 Reaction & 0.5392 & 0.6505 & 0.5055 & 0.5317 \\
\hline Stage 4 Reaction & 0.5257 & 0.6691 & 0.3835 & 0.5265 \\
\hline Stage 1 Loading Coefficient & 2.9068 & 3.1078 & 1.1073 & 1.1916 \\
\hline Stage 2 Loading Coefficient & 2.9432 & 2.8151 & 1.0911 & 1.0289 \\
\hline Stage 3 Loading Coefficient & 2.4203 & 2.3091 & 0.7729 & 0.7267 \\
\hline Stage 4 Loading Coefficient & 1.9652 & 2.0054 & 0.2942 & 0.3149 \\
\hline Stage 1 Flow Coefficient & 1.0301 & 1.2479 & 0.5611 & 0.6763 \\
\hline Stage 2 Flow Coefficient & 0.8661 & 1.0417 & 0.4636 & 0.5676 \\
\hline Stage 3 Flow Coefficient & 0.8733 & 0.8719 & 0.4640 & 0.4702 \\
\hline Stage 4 Flow Coefficient & 1.0662 & 0.9129 & 0.5117 & 0.4398 \\
\hline Stage 1 Efficiency & 0.8872 & 0.8988 & 0.9212 & 0.9300 \\
\hline Stage 2 Efficiency & 0.8671 & 0.8898 & 0.9068 & 0.9301 \\
\hline Stage 3 Efficiency & 0.8802 & 0.9037 & 0.9091 & 0.9399 \\
\hline Stage 4 Efficiency & 0.8832 & 0.8966 & 0.8780 & 0.9062 \\
\hline Stage 1 Horsepower & 605.2404 & 647.6505 & 1467.0664 & 1580.1257 \\
\hline Stage 2 Horsepower & 754.7814 & 721.8662 & 1780.5466 & 1678.8127 \\
\hline Stage 3 Horsepower & 718.4837 & 691.0576 & 1460.0514 & 1383.9444 \\
\hline Stage 4 Horsepower & 623.4244 & 641.3554 & 593.8541 & 640.9074 \\
\hline Stage 1 Pressure Ratio & 1.3928 & 1.4202 & 1.4083 & 1.4425 \\
\hline Stage 2 Pressure Ratio & 1.5880 & 1.5399 & 1.5892 & 1.5320 \\
\hline Stage 3 Pressure Ratio & 1.6204 & 1.5699 & 1.5195 & 1.4654 \\
\hline Stage 4 Pressure Ratio & 1.5925 & 1.6007 & 1.2073 & 1.2169 \\
\hline
\end{tabular}




\section{Acknowledgments}

The work presented in this paper was supported by NASA's Fundamental Aeronautics Program, Rotary Wing Project. The authors would like to thank Dr. Gerard Welch and the rest of the VSPT team at NASA Glenn Research Center for their support of this work.

\section{References}

${ }^{1}$ Gorton, S. A., López, I., and Theodore, C. R., "Subsonic Rotary Wing Project Overview," Presentation at the NASA ARMD Fundamental Aeronautics Program Technical Conference, March 13-15, 2012, Cleveland, Ohio.

${ }^{2}$ Acree, C. W., Yeo, H., and Sinsay, J. D., "Performance Optimization of the NASA Large Civil Tiltrotor," NASA TM2008-215359, 2008

${ }^{3}$ Johnson, W., Yamauchi, G. K., and Watts, M. E., "NASA Heavy Lift Rotorcraft Systems Investigation," NASA TP2005213467, 2005.

${ }^{4}$ D'Angelo, M., "Wide Speed Range Turboshaft Study," NASA CR-198380, 1995.

${ }^{5}$ Welch, G. E., "Assessment of Aerodynamic Challenges of a Variable-Speed Power Turbine for Large Civil Tilt-Rotor Application," NASA TM-2010-216758, 2010.

${ }^{6}$ Wilson, D. G. and Korakianitis, T., The Design of High-Efficiency Turbomachinery and Gas Turbines, Prentice-Hall, Upper Saddle River, New Jersey, 2nd ed., 1998.

${ }^{7}$ Mattingly, J., Elements of Propulsion: Gas Turbines And Rockets, AIAA Education Series, American Institute of Aeronautics and Astronautics, 2006.

${ }^{8}$ Welch, G. E., McVetta, A. B., Stevens, M. A., Howard, S. A., Giel, P. W., Ameri, A. A., To, W., Skoch, G. J., and Thurman, D. R., "Variable-Speed Power-Turbine Research at Glenn Research Center," NASA TM-2012-217605, 2012.

${ }^{9}$ Ameri, A. A., Giel, P. W., and McVetta, A. B., "Validation of a CFD Methodology for Variable Speed Power Turbine Relevant Conditions," NASA-TM-2013-217860, 2013.

${ }^{10}$ Flegel-McVetta, A. B., Giel, P. W., and Welch, G. E., "Aerodynamic Measurements of a Variable-Speed Power-Turbine Blade Section in a Transonic Turbine Cascade at Low Inlet Turbulence," NASA-TM-2013-218069, 2013.

${ }^{11}$ Jones, S. M., "Development of an Object-Oriented Turbomachinery Analysis Code within the NPSS Framework," NASA TM-2014-216621, 2014

${ }^{12}$ Claus, R. W., Evans, A. L., Lytle, J. K., and Nichols, L. D., "Numerical Propulsion System Simulation," Computing Sytems in Engineering, Vol. 2, No. 4, 1991, pp. 357-364.

13 "NPSS Team Wins Prestigious NASA Software of the Year Award," web, https://mdao.grc.nasa.gov/topstories.html.

${ }^{14}$ Ainley, D. G. and Mathieson, G. C. R., "A Method of Performance Estimation for Axial-Flow Turbines," 1951, British ARC, R \& M 1974.

${ }^{15}$ Dunham, J. and Came, P. M., "Improvements to the Ainley-Mathieson Method of Turbine Performance Prediction," Journal of Engineering for Power, 1970.

${ }^{16}$ Kacker, S. C. and Okapuu, U., "A Mean Line Prediction Method for Axial Flow Turbine Efficiency," Journal of Engineering for Power, Vol. 104, 1982, pp. 111-119.

${ }^{17}$ Moustapha, S. H., Kacker, S. C., and Tremblay, B., "An Improved Incidence Losses Prediction Method for Turbine Airfoils," Journal of Engineering for Power, Vol. 112, 1990, pp. 267-276.

${ }^{18}$ Smith, S. F., "A Simple Correlation of Turbine Efficiency," Journal of Royal Aeronautical Society, Vol. 69, July 1965, pp. $467-470$.

${ }^{19}$ Heath, C. and Gray, J., "OpenMDAO: Framework for Flexible Multidisciplinary Design, Analysis and Optimization Methods," AIAA-2012-1673, 53rd AIAA/ASME/ASCE/AHS/ASC Structures, Structural Dynamics and Materials Conference and 20th AIAA/ASME/AHS Adaptive Structures Conference, 23-26 April 2012, Honolulu, Hawaii.

${ }^{20}$ Suchezky, M. and Cruzen, G. S., "Variable-Speed Power-Turbine for the Large Civil Tilt Rotor," NASA CR-2012-217424, 2012.

${ }^{21}$ Ford, A., Bloxham, M., Turner, E., Clemens, E., and Gegg, S., "Design Optimization of Inicidence-Tolerant Blading Relevant to Large Civil Tilt-Rotor Power Turbine Applications," NASA-CR-2012-217016, 2012.

${ }^{22}$ Gill, P. E., Murray, W., and Saunders, M. A., "SNOPT: An SQP Algorithm for Large-Scale Constrained Optimization," SIAM Journal on Optimization, Vol. 12, 2002, pp. 976-1006. 